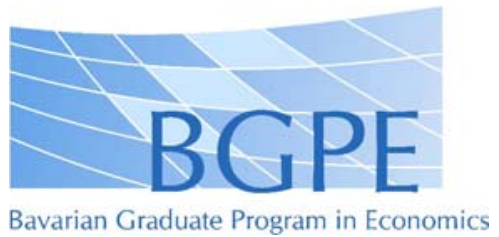

BGPE Discussion Paper

No. 38

\title{
Capital stock approximation using firm level panel data
}

A modified perpetual inventory approach

\section{Steffen Mueller}

January 2008

ISSN 1863-5733

Editor: Prof. Regina T. Riphahn, Ph.D.

Friedrich-Alexander-University Erlangen-Nuremberg

(c) Steffen Mueller 


\title{
Capital stock approximation using firm level panel data
}

A modified perpetual inventory approach

Steffen Mueller*

University of Erlangen - Nuremberg, Germany ${ }^{\dagger}$

January 2008

\begin{abstract}
Many recent studies exploring conditional factor demand or factor substitution issues use firm level panel data. A considerable number of establishment panels contains no direct information on the capital input, necessary for production or cost function estimation. Incorrect measurement of capital leads to biased estimates and casts doubt on any inference on output elasticities or input substitution properties. The perpetual inventory approach, commonly used for long panels, is a method that attenuates these problems. In this paper a modified perpetual inventory approach is proposed. This method provides more reliable measures for capital input when short firm panels are used and no direct information on capital input is available. The empirical results based on a replication study of Addison et al. (2006) support the conclusion that modified perpetual inventory is superior to previous attempts in particular when fixed effects estimation techniques are used. The method thus makes a considerable number of recently established firm panels accessible to more sophisticated production function or factor demand analyses.
\end{abstract}

Keywords: production function, capital input

JEL Classification: C81; D24; J23

\footnotetext{
*I wish to thank Regina T. Riphahn for helpful comments and Barbara Hanel for a lot of patience with my ideas.

${ }^{\dagger}$ Economics Department, Lange Gasse 20, D - 90403 Nuremberg; Phone: +49-9115302-344; e-mail: Steffen.Mueller@wiso.uni-erlangen.de
} 


\section{Introduction}

In recent years new establishment panel surveys have been created. For Germany these are e.g. the establishment panel of the $\mathrm{IAB}^{1}$, the Mannheim Innovation Panel (both since 1993) and the Hannover Panel (since 1994). Establishment panel data has the advantage to provide detailed micro data in a panel structure and thus is an excellent base for working on some of the most interesting questions in labor economics. Some of these questions are:

- What are the determinants of firm level labor demand?

- What is the influence of institutional regularities (works councils, collective agreements) on productivity?

- What are direction and extent of the substitution relations between capital and (different kinds of) labor?

- Is there any skill biased technological change?

To answer these questions the parameters of the firm's production or cost function (or of the derived factor demand function) have to be estimated. One requirement for estimating production or cost functions is the correct measurement of inputs. The major difficulty here is to measure capital input, because in many establishment panel data sets, e.g. in those mentioned above, direct information on capital stock is unavailable. Measurement errors in capital stock will lead to biased estimates and any inference based on such estimates could be misleading. This paper provides a method that, in comparison to previous studies, improves the approximation of capital stock substantially for the case that no direct information on capital stock is given and that the time-series dimension is short.

Many researchers use the investment expenditures of firms to approximate the unknown capital stock, i.e. investment expenditures are inserted directly into the production or cost function. Depending on the data, a variety of specifications is used. It is common to apply all available information about total investments like van Reenen (1997), only the replacements of the current year, see Bellmann and Schank (2000) or the sum of the last two years, see Addison et al. (2006). All these attempts entail the implicit assumption that investment expenditures reflect the necessary depreciation. If this is given, they are proportional to the unknown capital stock and control for the capital effect when estimating production functions, cost functions

\footnotetext{
${ }^{1}$ Institute for Employment Research of the Federal Labor Service in Germany (Institut fuer Arbeitsmarkt und Berufsforschung der Bundesagentur fuer Arbeit)
} 
or conditional factor demand functions. We call this approach the proportionality approach. The idea behind the proportionality approach is that depreciations are proportional to the capital stock, assuming a linear depreciation rate. Given that replacement investments are undertaken to replace depreciated capital, they are proportional to capital, too. Obviously, the proportionality assumption can only be fulfilled if replacement investments are used instead of total investments or net investments. In section 3 the problems that arise with the proportionality approach are investigated:

1. If the proportionality assumption hold, the approximated capital stock (the replacement investment expenditures) is proportional - with an unknown factor of proportionality - to the real capital stock. Adding net investments (reported in absolute value) to the replacement investments is not possible because this would destroy the proportionality. Thus information on net investments can not be used to approximate the capital stock.

2. The implicit assumption that replacements equal the unknown depreciation and are therefore proportional to the capital stock cannot be verified by data. Huge variations in the investment expenditures of a firm will lead to implausible variations in the (by assumption) proportional capital stock variable, e.g. zero investments in one year would cause a capital stock measure of zero for that year. This could cause measurement errors and a considerable attenuation bias.

To avoid these drawbacks a method is necessary that provides absolute values of capital stock and does not rely on the proportionality assumption of investments and capital stock. Perpetual inventory, i.e. continued adjustment of an inventory value by balancing inflows with outflows, is such an approach. In this paper it is modified to be feasible in short panels, too. Modified perpetual inventory consists of two steps with the first step as the modification. First, the absolute value of capital stock is computed, using the proportionality approach and information about average economic lives of capital goods. To provide a reliable alternative to the inventory value, these single capital stock values are than averaged to smooth variations caused by the investment expenditures they are based on. Second, traditional perpetual inventory is started from this average. To apply the new method only few information is necessary.

This paper is organized as follows: in section 2 the results of recent studies that use direct information on capital stock are compared with the results of analyses lacking this information and apply the proportionality approach. In section 3 the substantial differences found in section 2 are traced back to 
the problems of the proportionality approach and as a solution the modified perpetual inventory approach is proposed. In the fourth part the necessary information and assumptions for implementation are sketched. The proposed method is used to replicate a recent paper that applied the proportionality approach and the results are compared in section 5. The main conclusions are summarized in the final section.

\section{Literature}

In this section the results of studies with direct information on capital stock are compared with studies lacking this information. The latter applied the proportionality approach. The idea is to take the results of studies with information on capital stock as a benchmark and to see whether the proportionality approach is able to produce similar results without the direct capital stock information. The central measure for comparison is the output elasticity with respect to capital $\left(\epsilon_{Y, K}\right)$ because: this elasticity is a standard measure, it is reported in nearly any production function estimation and it is a capital related result that, conditional on the fact that the proportionality assumption is fulfilled, is estimated correct with the proportionality approach. In general, the analyzes without capital stock information listed in table 1 on page 6 report lower $\epsilon_{Y, K}$, e.g. because of measurement errors in the capital variables due to simplifying assumptions made in the proportionality approach $^{2},{ }^{3}$.

For all studies the fixed effects estimation results are lower than the OLS results. One interpretation is that, as the variance in the capital variable is reduced in the within estimation, other misspecifications overwhelm the remaining signal in the data. Besides others, the lack of information on time-varying variables, e.g. on output prices or on capacity utilization for capital and labor, is a possible misspecification. Another interpretation is that an existing measurement error problem increases in the case of within estimation if the serial correlation in the measurement error is lower than the one in the true capital stock ${ }^{4}$. Given the empirical results of this paper

\footnotetext{
${ }^{2}$ It is possible, of course, that the proportionality approach estimates are correct and the others are biased upwards. Note, that for industry or country level data these elasticities were usually estimated between 0.2 to 0.3, too (e.g. Levy (1994) or Hsing (1996)).

${ }^{3}$ In table 1 on page 6 we listed no study that deals with the problem of simultaneity (see e.g.Griliches and Mairesse (1998) or Olley and Pakes (1996)). The reason is that no analysis was found that approaches the simultaneity problem and uses the proportionality approach. For the sake of comparability the selected studies with information on capital stock do neither.

${ }^{4}$ See e.g. Bound, Brown, and Mathiowetz (2001).
} 
it is suggested that the major reason for the sharp downfall in $\epsilon_{Y, K}$ found with the proportionality approach and illustrated in table 1 is the inaccurate measurement of the capital stock.

A convincing production function estimation can only be done if inputs and output are measured correctly. Presumably, there exist only so few production function estimations based on establishment panels without direct information on capital stock because the capital stock information is missing and existing capital stock approximation methods are not reliable. A reliable approximation method for the capital input would make a considerable number of recently established, rich firm level panel data sets accessible for more sophisticated studies in this field.

\section{The modified perpetual inventory approach}

This section starts with an inspection of the two major problems of the proportionality approach and concludes with the modified perpetual inventory approach as the solution to this problems.

\subsection{Proportionality}

A first drawback of working only with a proportional value is that information about the absolute value of the net investment cannot be taken into consideration. Adding them to the replacement investment expenditures would obviously destroy the assumed proportionality. The second is that if this proportional value is used to estimate cost- or production function parameters or e.g. to derive estimates from conditional factor demand functions, then the estimates for capital stock will be biased upwards ${ }^{5}$. Assuming linear depreciation, the unknown factor of proportionality with respect to the absolute value of capital stock is the average depreciation rate. This information is not given in many establishment data sets.

One promising way to estimate it is to use industry level information. In this paper data from the German Federal Statistical Office (GFSO) is used. It provides the composition of each industry capital stock into structures and equipment ${ }^{6}$ and data on the average economic lives of structures and equipment ${ }^{7}$ (the reciprocal of the linear depreciation rate). Combining both by constructing the harmonic mean of the economic lives of structures and equipment gives the reciprocal of the average linear depreciation rate in a

\footnotetext{
${ }^{5}$ Of course they are not biased if a logarithmic functional form is used for estimation.

${ }^{6}$ Fachserie 18, Reihe 1.3 (from 2005 on, Reihe 1.4)

${ }^{7}$ Available on request from the GSFO.
} 


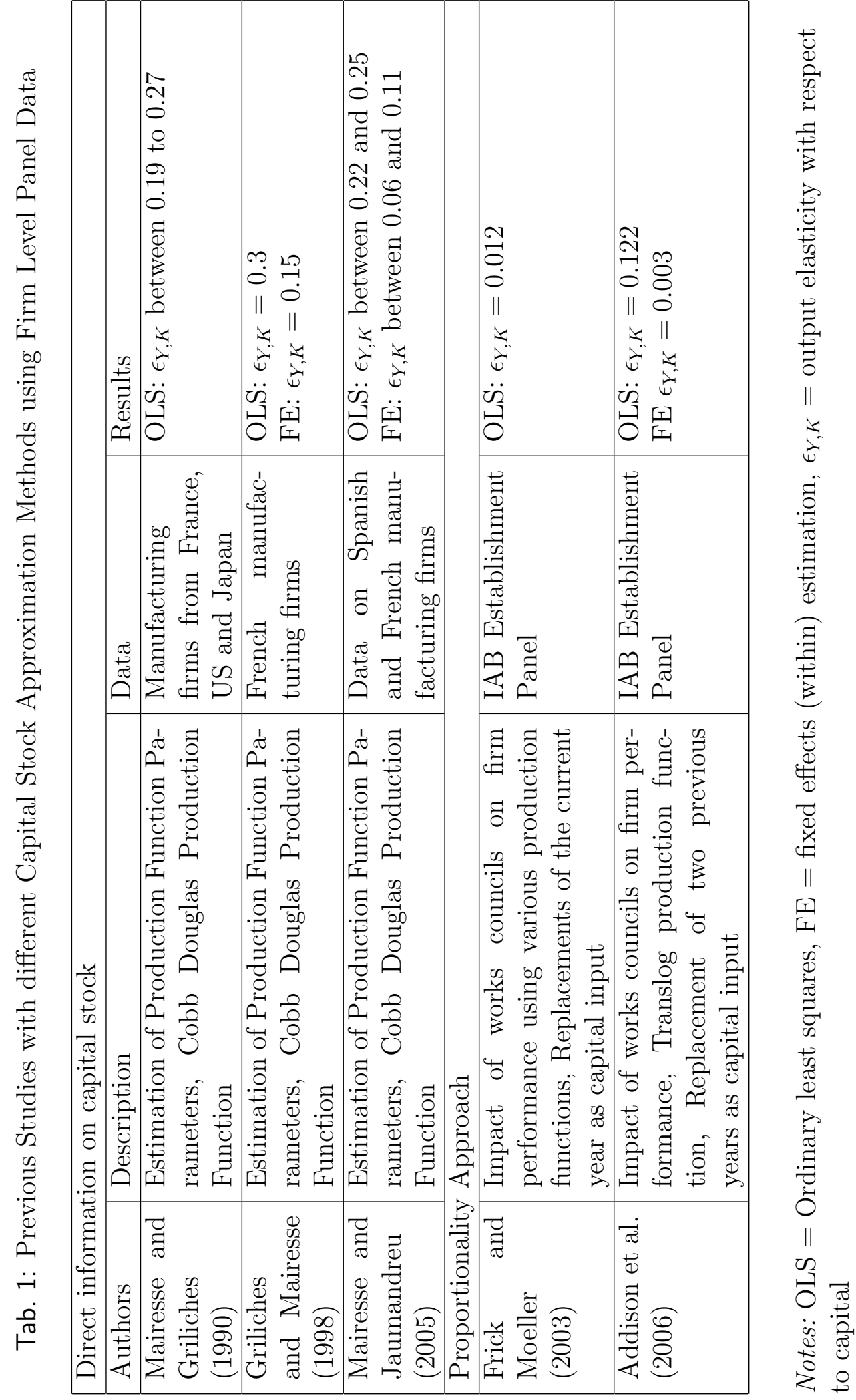


given industry:

$$
\frac{1}{D R}=\frac{K_{\text {total }}}{\left(K_{\text {structure }} / L_{\text {structure }}\right)+\left(K_{\text {equipment }} / L_{\text {equipment }}\right)},
$$

with $K$ for the capital stock, $L$ for average economic life and $D R$ for the depreciation rate. In order to combine industry data with establishment data one has to assume that every firm within an industry has an identical composition of capital stock (assumption 1) and thus the same average depreciation rate. For competitive industries this assumption seems to be realistic because in the long run only those firms with the superior production technology will survive. Non-competitive sectors such as the public sector or non-profit organizations may not tend to fulfill assumption 1 and should be excluded from the sample.

Multiplying replacements with the reciprocal of the average depreciation rate gives the absolute value of the capital stock:

$$
K_{t}=I R_{t} * \frac{1}{D R}+I N_{t}
$$

with IR for replacement investments, $t$ as a time index and IN for net investments, whereas most former studies had to apply proportional values ${ }^{8}$. We call this the augmented proportionality approach.

\subsection{Moving averages}

In section 3.1 the problem of the unknown factor of proportionality is solved by using industry level data, but the approach so far is still similar to the proportionality approach. This is the case because equation 2 depends heavily on the assumption that the reported expenditures for replacement investments equal the unobserved depreciation. In other words: one has to assume that every firm completely replaces its depreciated capital every year (assumption 2 ). This is the major problem of the proportionality approach because if the assumption is not valid, the classical measurement error problem occurs ${ }^{9}$ and estimates will be attenuated to zero ${ }^{10}$.

\footnotetext{
${ }^{8}$ A similar approach can be found in Ornaghi (2006).

${ }^{9}$ One might argue that the classical measurement error logic, see e.g. Bound et al. (2001), is not applicable because of the potential endogeneity of capital in the true model. However, as we are comparing capital approximation methods this potential problem touches all methods in the same way.

${ }^{10}$ Whether violations of assumption 2 induce the measurement error is tested and discussed in section 5 .
} 
Several studies, e.g. Caballero, Engel, and Haltiwanger (1995), Doms and Dunne (1998), Power (1998) or Nilsen and Schiantarelli (2003) clearly show that assumption 2 is very unlikely to hold at the establishment level. The authors claim that investments are lumpy and many firms report zero investments for certain years. A capital stock computed with the proportionality approach would be zero if investments are zero. In fact capital is a rather stable input for most firms. High variations in replacements are thus a clear sign that assumption 2 fails. Some authors recognize this problem and use the average or sum of some past investment vintages to smooth the volatility in a firm's investment expenditures. Using averages of investment vintages means that assumption 2 has to hold only on average, i.e. the sum of depreciations equals the sum of replacements in a period that is longer than one year.

\subsection{Perpetual inventory}

Clearly, the use of averages alone is not a satisfying solution to the measurement error problem. The measurement error problem is still present, maybe it is weakened. To overcome this general problem one has to drop assumption 2. One common capital stock approximation method that does not rely on assumption 2 is the perpetual inventory method. Unfortunately this method is only feasible for long time series that are not available in most establishment panel data sets. The central idea of this paper is to modify perpetual inventory in a way that makes it feasible for short panels.

Perpetual inventory is an accounting method. Capital inflows (total investments) are balanced with capital outflows (depreciation, sales from capital stock)

$$
\Delta K=\left(I R_{t}-D_{t}\right)+\left(I N_{t}-D_{t}^{I N}\right)-S A L E S .
$$

The resulting difference is then added to the capital stock of the previous year

$$
K_{P I M}=K_{t-1}+\Delta K
$$

with $D_{t}$ as the expected depreciation of the capital stock at the beginning of the year, $D_{t}^{I N}$ as the depreciation regarding to the net investments of the current year and $K_{P I M}$ as the capital stock at the end of the current year. Because perpetual inventory is a type of accounting rather than an approximation method it should lead to more reliable results.

Because perpetual inventory always rests on the capital stock of the previous year, this is an endless chain and the fundamental problem is to find a starting value. One solution is to account for investment vintages over a long period of time and to evaluate the depreciation rate of every vintage. If 
one knows the depreciation rate one knows the amount of capital of a certain investment vintage that is left in the capital stock at a certain point in time. This procedure is often not feasible if the unit of observation is the firm rather than the industry because if e.g., the depreciation rate of a certain firm's capital stock is 0.04 , one has to observe a firm over 25 years before only known investment vintages are left in the capital stock and thus the latter is computable. Most establishment panels cannot provide this data; first because only few firms are observed over 25 years (panel mortality, plant closure) and second because some panel data sets have been established only 10 or 15 years ago.

Modified perpetual inventory overcomes this problem by using the moving average of equation 2 as a starting value for the perpetual inventory procedure. In other words, modified perpetual inventory uses the proportionality approach to derive the starting value and classical perpetual inventory to compute the capital stocks of subsequent years.

\section{Implementation of modified perpetual inventory}

In general, information on the amount of replacements and net investments at the firm level, the composition of capital stock at the industry level and the knowledge about the average depreciation rate of capital structures and equipments are necessary to apply modified perpetual inventory. After an average depreciation rate at the industry level is computed, see section 3.1, one has to know to which industry a certain firm belongs. To assign the industry level information to the single firm of this industry assumption 1 is necessary. This information is sufficient to compute the absolute value for every firm's capital stock in a given year.

To construct moving averages as described in section 3.2 no further information is necessary. The crucial point here is to determine a reasonable number of periods of support for the moving average. The more periods a panel contains the longer the moving average can be chosen. Recall that the simple moving average is only a starting point for perpetual inventory, i.e. the average is the first observation for capital stock. When increasing the number of periods of support for the moving average there is a tradeoff between loss of observations (the first years in the panel) and the intended degree of smoothing the single investment vintages used for the computation of the starting value. Table 2 shows the magnitude of smoothing when extending the number of periods of support for the starting value (SMA), computed from the IAB Establishment Panel ${ }^{11}$. SMAn is a simple mov-

\footnotetext{
${ }^{11}$ For details on the establishment panel see http://betriebspanel.iab.de/.
} 
ing average of the augmented proportionality approach (equation 2) with $n$ years of support. From the table one can see that e.g. extending the period of support from two (SMA2) to three years (SMA3) causes a decrease in the within standard deviation by more than 40 percent. At the same time the number of observations for capital stock (applying modified perpetual inventory) decreased only from 11,175 to $11,114^{12}$.

Tab. 2: Variations in moving averages of different length

\begin{tabular}{|c|c|c|c|c|}
\hline variable & variation & Mean & Standard Deviation & Observations \\
\hline \multirow{3}{*}{ SMA1 } & overall & $7.14 * 10^{7}$ & $5.27 * 10^{8}$ & \multirow{3}{*}{$\begin{array}{l}\text { Obs }=20495 \\
\text { Firms }=5474 \\
\text { T-bar }=2.27\end{array}$} \\
\hline & between & & $4.28 * 10^{8}$ & \\
\hline & within & & $2.42 * 10^{8}$ & \\
\hline \multirow{3}{*}{ SMA2 } & overall & $8.81 * 10^{7}$ & $5.57 * 10^{8}$ & \multirow{3}{*}{$\begin{array}{l}\text { Obs }=14264 \\
\text { Firms }=5527 \\
\text { T-bar }=2.58\end{array}$} \\
\hline & between & & $4.70 * 10^{8}$ & \\
\hline & within & & $2.06 * 10^{8}$ & \\
\hline \multirow{3}{*}{ SMA3 } & overall & $9.51 * 10^{7}$ & $5.66 * 10^{8}$ & \multirow{3}{*}{$\begin{array}{l}\text { Obs }=8737 \\
\text { Firms }=4102 \\
\text { T-bar }=2.13\end{array}$} \\
\hline & between & & $5.05 * 10^{8}$ & \\
\hline & within & & $1.18 * 10^{8}$ & \\
\hline
\end{tabular}

Notes: Data from IAB Establishment Panel, waves 1996 - 2000, SMAn is a simple moving average of equation 2 with $n$ years of support, SMA is measured in million German marks, own calculations.

After choosing a particular SMA as a starting value for perpetual inventory, the latter is applied. The additional information necessary for it is every firm's depreciation. Information on the sales of capital goods would be useful, too. For my analysis the latter was not given and therefore has not been considered. The depreciation has to be computed for net investments and the capital stock at the beginning of the period, see equation (3) on page 8. Using information on average economic lives of capital goods, the depreciation of net investments are easy to compute if their type (e.g. plants, buildings or IT) is known. Information on depreciation of the previous years' capital stock are more difficult to get. I computed it by multiplying previous years' capital stock by its average depreciation rate, again assuming a linear depreciation rate. Clearly, this depreciation rate has to be found before. For the first year of perpetual inventory the depreciation rate of a firm equals that of the industry level by assumption 1 . From the second year on it is

\footnotetext{
12 The number of observations for capital stock can not be seen from the table. What can be seen is the maximum number of starting values computable from this data.
} 
a weighted average of the depreciation rate of the capital stock at the beginning of the previous year and the depreciation rate of previous year's net investment ${ }^{13}$.

\section{Empirical Application}

Section 3 showed why the method presented in this paper is superior to previous attempts from a theoretical point of view. Now the plausibility of the method is examined empirically. Therefore in this section the modified perpetual inventory is applied in a replication study of Addison, Schank, Schnabel, and Wagner (2006).

\subsection{Replication estimation}

The original paper uses the IAB Establishment Panel to examine whether the presence of a works council influences the firm's productivity and the works council effect is controlled for capital input. Capital input is approximated using the replacement investments of the current and the previous year, i.e. the proportionality approach. In the replication study, capital input will be approximated using the modified perpetual inventory approach. The aim of the replication study is to compare the estimated coefficients of the capital related variables using both approaches. The central criteria for comparison are the elasticity of output with respect to capital and the statistical significance of the capital regressors. The two different capital stock approximation methods lead to different samples. To compare the methods directly, only observations that appear in both samples are used for estimation ${ }^{14}$.

Following Addison et al. (2006) a translog production function with total sales $(Y)$, inputs labor $(N)$ and capital $(K)$ and a vector of other explanatory variables $(Z)$ is used:

$$
\ln Y=\beta_{0}+\beta_{1} \ln N+\beta_{2} \ln K+\beta_{11} \frac{(\ln N)^{2}}{2}+\beta_{22} \frac{(\ln K)^{2}}{2}+\beta_{12} \ln N \ln K+\gamma Z+\epsilon,
$$

\footnotetext{
${ }^{13}$ In practice the computation of firm specific depreciation rates is difficult. Due to implausible variations in the investment variables in the examined data the depreciation rate turned out to be negative in few cases. To avoid this problem I decided to use the industry level information for the depreciation rate (see section 3.1) for all firms instead of firm specific values. The results differ only slightly.

${ }^{14}$ I am especially grateful to Thorsten Schank for providing the ID's of the firms that Addison et al. (2006) used for estimation.
} 
and the elasticity of output with respect to capital is computed as follows:

$$
\epsilon_{Y, K}=\frac{\partial \ln Y}{\partial \ln K}=\beta_{2}+\beta_{22} \ln K+\beta_{12} \ln N .
$$

The estimation results are reported in table 3 on page 13 . The first two columns show the results of pooled OLS estimations based on the two different capital stock approximation methods. Columns three and four show the results for fixed effects estimation. According to Addison et al. (2006) we used a within estimator that only takes account of the deviations from the within firm mean.

While the OLS estimation show no fundamental differences, for the fixed effects estimation both capital coefficients, i.e. $\ln K$ and $1 / 2(\ln K)^{2}$, are zero with Addison et al.'s (2006) method and significantly different from zero in the replication analysis. The estimate for $\epsilon_{Y, K}$ obtained with Addison et al.'s (2006) capital stock approximation is also near zero while modified perpetual inventory gives an $\epsilon_{Y, K}$ of 0.110 using exactly the same observations ${ }^{15}$. Mairesse and Jaumandreu (2005) estimated a production function with firm level data and information on book values of capital stock. They estimated output elasticities between 0.06 and 0.11 ; results that are very similar to the results we found with the modified perpetual inventory approach. Taking the studies with information on capital stock as a benchmark (see table 1 on page 6 ), the empirical results of the replication study are more plausible than the results of Addison et al. (2006). This supports the new method applied in this study.

\subsection{Interpretation and Robustness}

When comparing the proportionality approach with modified perpetual inventory one is interested in isolating the reasons behind the different results of the original and the replication estimation. There are three differences in the methods that could explain the different results:

1. information on net investments are exclusively used in the replication study,

2. in the replication study a three years moving average is applied while only two years are used in the original study and

15 The elasticities are estimated at sample means. The sample mean of labor is 354 employees. Addison et al.'s (2006) capital stock approximation method gives a sample mean of 5.3 million German Mark for capital, with modified perpetual inventory this amounts to 149 million. 
Tab. 3: Results of the replication study

\begin{tabular}{|c|c|c|c|c|}
\hline Regression Method & \multicolumn{2}{|c|}{ Ordinary Least Squares } & \multicolumn{2}{|c|}{ Fixed Effects } \\
\hline Studies & Addison & Mueller & Addison & Mueller \\
\hline \multirow[t]{2}{*}{ Works council (dummy: 1=yes) } & 0.219 & 0.200 & -0.010 & -0.009 \\
\hline & {$[5.77]^{* * *}$} & {$[5.21]^{* * *}$} & {$[0.30]$} & {$[0.26]$} \\
\hline \multirow[t]{2}{*}{ Number of employees $(\ln N)$} & 1.161 & 1.210 & 0.574 & 0.957 \\
\hline & {$[13.47]^{* * *}$} & {$[10.56]^{* * *}$} & {$[8.68]^{* * *}$} & {$[7.32]^{* * *}$} \\
\hline \multirow[t]{2}{*}{ Capital stock $(\ln K)$} & -0.099 & -0.187 & 0.019 & -0.319 \\
\hline & {$[1.43]$} & {$[1.87]^{*}$} & {$[0.69]$} & {$[3.09]^{* * *}$} \\
\hline \multirow[t]{2}{*}{$1 / 2(\ln N)^{2}$} & 0.001 & -0.005 & 0.012 & 0.042 \\
\hline & {$[0.05]$} & {$[0.23]$} & {$[0.84]$} & {$[2.31]^{* *}$} \\
\hline \multirow[t]{2}{*}{$1 / 2(\ln K)^{2}$} & 0.025 & 0.026 & 0.002 & 0.035 \\
\hline & {$[2.74]^{* * *}$} & {$[2.82]^{* * *}$} & {$[0.70]$} & {$[4.21]^{* * *}$} \\
\hline \multirow[t]{2}{*}{$\ln N \ln K$} & -0.021 & -0.020 & -0.010 & -0.040 \\
\hline & {$[1.90]^{*}$} & {$[1.70]^{*}$} & {$[2.30]^{* *}$} & {$[3.72]^{* * *}$} \\
\hline Investment in ICT & 0.111 & 0.123 & 0.022 & 0.022 \\
\hline (dummy:1=yes) & {$[4.79]^{* * *}$} & {$[5.29]^{* * *}$} & {$[2.39]^{* *}$} & {$[2.41]^{* *}$} \\
\hline State of technology & -0.084 & -0.080 & -0.004 & -0.005 \\
\hline $\begin{array}{l}\text { (index: } 1=\text { state of the art; } \\
5=\text { obsolescent) }\end{array}$ & {$[5.59] * * *$} & {$[5.31]^{* * *}$} & {$[0.75]$} & {$[0.69]$} \\
\hline \multirow[t]{2}{*}{ Parttime workers (percentage) } & -1.052 & -1.038 & -0.089 & -0.087 \\
\hline & {$[10.38]^{* * *}$} & {$[10.29]^{* * *}$} & {$[1.73]^{*}$} & {$[1.68]^{*}$} \\
\hline \multirow[t]{2}{*}{ Apprentices (percentage) } & -1.034 & -1.034 & 0.120 & 0.157 \\
\hline & {$[5.78]^{* * *}$} & {$[5.76]^{* * *}$} & {$[1.04]$} & {$[1.36]$} \\
\hline \multirow[t]{2}{*}{ Skilled workers (percentage) } & 0.312 & 0.298 & 0.033 & 0.033 \\
\hline & {$[6.03]^{* * *}$} & {$[5.73]^{* * *}$} & {$[1.37]$} & {$[1.35]$} \\
\hline Collective Agreement & 0.090 & 0.090 & -0.009 & 0.009 \\
\hline (dummy: 1=yes) & {$[3.16]^{* * *}$} & {$[3.17]^{* * *}$} & {$[0.63]$} & {$[0.64]$} \\
\hline \multirow[t]{2}{*}{ Constant } & 12.595 & 13.055 & 14.084 & 15.376 \\
\hline & {$[41.15]^{* * *}$} & {$[22.42]^{* * *}$} & {$[74.36]^{* * *}$} & {$[20.93]^{* * *}$} \\
\hline \multirow{3}{*}{$\begin{array}{l}\text { Output elast. at sample means } \\
\epsilon_{Y, N} \\
\epsilon_{Y, K}\end{array}$} & & & & \\
\hline & 0.839 & 0.814 & 0.496 & 0.446 \\
\hline & 0.158 & 0.186 & -0.003 & 0.110 \\
\hline Observations & \multicolumn{4}{|c|}{6077} \\
\hline Firms & \multicolumn{4}{|c|}{2459} \\
\hline Year Dummies & \multicolumn{2}{|c|}{ yes } & \multicolumn{2}{|c|}{ yes } \\
\hline$R^{2}$ overall & 0.91 & 0.91 & 0.84 & 0.84 \\
\hline
\end{tabular}

Notes: Merged Sample, Translog Production Function (1997 - 2000; dependent variable: total sales $(\log \mathrm{Y})$ ); firms with at least five employees; $\mathrm{t}$ values in brackets; ${ }^{*}, * * * * *$ denote significance at the $0.1,0.05$ and 0.01 level, respectively. 
3. the drop of assumption 2, what is equivalent to the transition from a proportionality approach to a (modified) perpetual inventory approach.

The first two issues could be handled within a proportionality framework, too. If they explain the difference in the results no modified perpetual inventory approach is necessary. The third point characterizes the methodological innovation in this paper. Only if the transition to perpetual inventory explains a substantial part of the improvement in the results the new method is an improvement, too. To isolate the effect of the third point, one has to compare the results of the modified perpetual inventory approach with the results of a method that differs only in this point from modified perpetual inventory. For these purposes the proportionality approach is augmented in way that it uses information on net investments (point 1) and the same number of supporting years for the moving average as the modified perpetual inventory approach (point 2). The estimation is repeated with this augmented proportionality approach (SMA) and modified perpetual inventory (MPI) to compare the results.

To additionally check the robustness of the difference in the results, both methods are varied in the number of supporting years for the moving average. As a result we compare three approximation methods: first, modified perpetual inventory based on a three year moving average (MPI3) compared to the augmented proportionality approach based on a three years moving average (SMA3), second, MPI2 versus SMA2 and third, MPI1 versus SMA1. If the results of MPIn are always superior to the corresponding results of SMAn, the transition to perpetual inventory explains the different results.

Table 4 on page 15 shows the estimated $\epsilon_{Y, K}$ for different capital stock approximation and estimation methods. MPIn is the modified perpetual inventory approach with a starting value that is computed from a moving average of length $n$ (MPI3 is thus the method applied to compute the capital value for the replication study discussed above). SMAn is a simple moving average of $K_{t}$ (the augmented proportionality approach from equation 2 on page 7) with length $n$. Recall that the SMA are in absolute value and use information about net investments and that the switch to perpetual inventory done in the MPIn but not done in the SMAn is therefore the only difference. The four cells are numbered to ease discussion. The switch to perpetual inventory can be seen when going from the right column to the left. Little difference exists between cells IV and III, while the major contribution of modified perpetual inventory can be seen when cell II is compared to cell I. Due to the setting one can conclude that the transition to perpetual inventory is the only reason for the improved results in fixed effects estimation. What is the econometrical explanation for the improvement? The 
Tab. 4: Summary for different capital stock approximation methods

\begin{tabular}{|l|l|l|}
\hline $\begin{array}{l}\text { Estimation of } \\
\epsilon_{Y, K}\end{array}$ & $\begin{array}{l}\text { Modified Perpetual Inven- } \\
\text { tory (MPI) }\end{array}$ & $\begin{array}{l}\text { Simple Moving Averages } \\
\text { (SMA) }\end{array}$ \\
\hline Fixed Effects & I & II \\
Estimation & MPI1: $\epsilon_{Y, K}=0.06$ & $\begin{array}{l}\text { SMA1: } \epsilon_{Y, K}=0.02 \\
\text { SMA2: } \epsilon_{Y, K}=0.01\end{array}$ \\
& MPI2: $\epsilon_{Y, K}=0.08$ & SMA3: $\epsilon_{Y, K}=0.01$ \\
\hline Pooled OLS & III $\epsilon_{Y, K}=0.11$ & IV \\
Estimation & MPI1: $\epsilon_{Y, K}=0.15$ & SMA1: $\epsilon_{Y, K}=0.15$ \\
& MPI2: $\epsilon_{Y, K}=0.17$ & SMA2: $\epsilon_{Y, K}=0.15$ \\
& MPI3: $\epsilon_{Y, K}=0.19$ & SMA3: $\epsilon_{Y, K}=0.17$ \\
\hline
\end{tabular}

Notes: The numbers after MPI and SMA denote the number of periods of support for the moving average (in years) the capital approximation is based on.

transition to perpetual inventory causes the drop of the proportionality assumption. The proportionality assumption is expected to cause substantial measurement errors (see section 3.2). Thus, to renounce the proportionality assumption reduces the measurement error and this explains the improved results. Further, from the table it can been seen that pooled OLS estimates (cells III and IV) are generally higher than the fixed effects estimates, supporting the findings in the replication study. When applying the fixed effects estimator instead, the decrease in $\epsilon_{Y, K}$ is higher for the SMA approximation.

One last question to discuss is why the difference in the results of modified perpetual inventory and the augmented proportionality approach nearly completely vanishes in the OLS estimation case. The OLS estimator considers the within and the between dimension of the data. We have seen above that modified perpetual inventory is superior to the augmented proportionality approach in the within dimension. What could cause the noise in the between dimension that offsets the better approximation in the within firm dimension?

To explain this we have to go back to the creation of the starting values for perpetual inventory. The starting value consists of an average of capital stock values that is computed with the augmented proportionality approach, i.e. averages of equation 2 on page 7 . Keeping in mind the problems of the proportionality approach one has to expect measurement errors in the start- 
ing value, too. Given this fact, perpetual inventory starts from an inaccurate value. While with perpetual inventory there is convergence against the true value in the long run, the error persists in the short run. Hence we cannot hope to overcome this error on account of the shortness of the panels under consideration. The consequence is a noisy measure of the level of capital stocks of different firms, inducing noise to the between dimension of the OLS estimation.

In opposition to modified perpetual inventory, the proportionality approach uses moving averages of investment vintages. Hence there is hope that an error in one year is followed by an error in the opposite direction, i.e. the errors are not persistent but random. Therefore, on average, the level of capital stock can be expected to have the correct magnitude. Thus, the between firm information derived with the proportionality approach is expected to be more correct.

To sum up: the proportionality approach causes a measurement error problem. For the within dimension of the data the measurement error problem can be alleviated via the switch to perpetual inventory. Considering the between and the within dimension, i.e. the OLS case, the advantage of modified perpetual inventory decreases.

\section{Summary}

A more accurate method for firm level capital stock approximation than applied so far is proposed for establishment panel data sets that contain only short investment time series and no direct information on capital stock. The utility of the new method is twofold; results of existing studies can be reviewed critically and a lot of rich establishment panel data sets become accessible to more sophisticated production function and factor demand analyses that e.g. control for the endogeneity of the capital input decision.

In former studies for long time series the perpetual inventory approach was widely used. For short establishment panel data sets, the firms' investments were used to approximate their capital stock, i.e. the proportionality approach. In this paper it is shown that the proportionality approach has two major drawbacks; (a) that only a proportional value for capital is computed and (b) that it relies on the assumption that observed replacements equal unobserved depreciations. The latter has to be rejected given highly volatile investment expenditures and reported zero investments. Violations of this assumption indicate the presence of the classical measurement error problem.

Modified perpetual inventory solves both problems by augmenting the 
proportionality approach to compute a starting value that allows one to perform traditional perpetual inventory, an accounting method that is not based on the doubtful assumption of investments equaling depreciations and that therefore is expected to yield more reliable results. To evaluate whether the modified perpetual inventory yields better estimates for the effect of capital a replication study has been performed. For fixed effects estimation using the within estimator, the new method yields significant coefficients for the capital regressors and a value of 0.11 for the output elasticity with respect to capital input. Applying the old method to the same observations gives insignificant estimates and an elasticity of output with respect to capital of zero. Further, the new method yields results that are close to what was found when capital stock information is given and similar estimation methods are used. This is seen as a strong indication for an improved capital stock approximation using modified perpetual inventory.

\section{References}

Addison, J. T., T. Schank, C. Schnabel, And J. Wagner (2006): "Works Councils in the Production Process," Schmollers Jahrbuch, (126), 251-283.

Bellmann, L., And T. Schank (2000): "Innovations, Wages and Demand for Heterogeneous Labor: New Evidence from a Matched EmployerEmployee Data Set," Bonn: IZA Discussion Paper, (112).

Bound, J., C. Brown, and N. Mathiowetz (2001): Measurement Error in Survey Data, in James J. Heckman and Leamer, Edward (ed.), Handbook of econometrics, vol. 5, Amsterdam: North-Holland, 3705 - 3843.

Caballero, R. J., E. M. R. A. Engel, and J. C. Haltiwanger (1995): "Plant-Level Adjustment and Aggregate Investment Dynamics," Brookings Papers on Economic Activity, (2), 1 - 39.

Doms, M., And T. Dunne (1998): "Capital Adjustment Patterns in Manufacturing Plants," Review of Economic Dynamics, 1(2), 409-429.

Frick, B., ANd I. Moeller (2003): "Mandated Works Councils and Firm Performance: Labor Productivity and Personnel Turnover in German Establishments," Schmollers Jahrbuch, 3, 423-454.

Griliches, Z., And J. MaIResse (1998): Production Functions: The search for identification, in S. Strom (ed.) The Ragnar Frisch Centennial Symposium, Cambridge: Cambridge University Press, 192 - 231. 
Hsing, Y. (1996): "An Empirical Estimation of Regional Production Functions for the U.S. Manufacturing Industry," Annals of Regional Science, 30(4), $351-358$.

LEvy, D. (1994): "Output, Capital, and Labor in the Short and Long Run," Southern Economic Journal, 60(4), 946 - 960.

Mairesse, J., And Z. Griliches (1990): Heterogeneity in Panel Data: Are there stable production functions?, in P. Champsaur et al. (eds.), Essays in Honour of Edmond Malinvaud, vol. 3, Empirical Economics, Cambridge, Mass. and London: MIT Press, 3705 - 3843.

Mairesse, J., and J. Jaumandreu (2005): "Panel-Data Estimates of the Production Function and the Revenue Function: What Difference Does It Make?," Scandinavian Journal of Economics, 107(4), 651 - 672.

Nilsen, O. A., and F. Schiantarelli (2003): "Zeros and Lumps in Investment: Empirical Evidence on Irreversibilities and Nonconvexitites," Review of Economics and Statistics, 85(4), 1021 - 1037.

Olley, G. S., And A. PAKes (1996): "The dynamics of productivity in the telecommunications equipment industry," Econometrica, 64(6), 1263 1297.

Ornaghi, C. (2006): "Assessing the Effects of Measurement Errors on the Estimation of Production Functions," Journal of Applied Econometrics, 21(6), $879-891$.

Power, L. (1998): "The Missing Link: Technology, Investment, and Productivity," Review of Economics and Statistics, 80(2), 300 - 313.

VAn ReEnen, J. (1997): "Employment and Technological Innovation: Evidence from U.K. Manufacturing Firms," Journal of Labor Economics, 15(2), 255-284. 